\title{
Developing a Software to Evaluate Hydrological Effect of Forest Change
}

\author{
Zuozhu Meng ${ }^{1}$, Mingfang Zhang ${ }^{1,2^{*}}$, Yiping $\mathrm{Hou}^{1}$ and Le $\mathrm{Yu}^{1}$ \\ ${ }^{1}$ School of Resources and Environment, University of Electronic Science and Technology of China, Chengdu, China 611731 \\ ${ }^{2}$ Center for Information Geoscience, University of Electronic Science and Technology of China, Chengdu, China 611731 \\ ${ }^{*}$ Corresponding author
}

\begin{abstract}
Water conservation is one of the most important functions of forest ecosystems. An efficient assessment on changes in water conservation capacity of a forest watershed, especially for a large watershed is essential for water resources and forest management. In order to simplify the assessment procedures, we took advantage of ENVI / IDL and ArcGIS Engine / C \# .NET hybrid programming languages and developed an assessment software (Forest Water Assessment Tool, FWAT) for calculating forest water conservation capacity based on the integrated water storage capacity method. In addition, we used the Meijiang watershed as an example to demonstrate the application of FWAT to calculate water conservation capacity. The spatial distribution and statistical results of forest water conservation capacity in the Meijiang watershed were successfully calculated by FWAT. It shows that FWAT is a very useful tool that can be widely used in evaluating water conservation capacity of forested watersheds and support decision-makers with a quick access to scientific information regarding forest and water management.
\end{abstract}

Keywords-water conservation; software; hydrological effect; forest change

\section{INTRODUCTION}

Forest ecosystem as the largest and most widely distributed one in terrestrial ecosystems plays an important role in human well-beings and development [1]. The water conservation function of forest ecosystems in terms of rain interception, runoff regulation, soil water storage and water purification attracts more and more attention due to the increased demand for water resources and the deterioration of the water environment $[2,3]$. The rapid development of remote sensing and geo-information technology makes it feasible to calculate and analyze water conservation capacity of forests at a larger spatial scale. Remote Sensing (RS) mainly provides information on spatiotemporal dynamics of forests by the acquisition, processing and extraction of image data. And the core of Geographic Information System(GIS) is the storage, management, spatial analysis and application of spatial data related to forest vegetation, climate and topography[4, 5].
However, the calculation of water conservation capacity and its spatiotemporal pattern of a large watershed can be time-consuming since it involves processing of various data on vegetation, topography, and climate. In order to provide natural resources managers with a quick assessment on forest water conservation capacity and its spatiotemporal dynamics, it is in critical need to develop an evaluation tool that can be easily and widely applied. Therefore, based on the integrated water storage capacity method, this study used ENVI / IDL, ArcGIS Engine / C \# .NET secondary development and hybrid programming to design and develop a software for evaluating forest water conservation capacity.

\section{METHOD, SOFTWARE DESIGN AND FUNCTION MODULES}

\section{A. Method for Calculating Water Conservation Capacity}

The calculation methods of forest water conservation capacity include soil water storage capacity method, integrated water storage capacity method, water balance method and so on. However, these methods have some limitations; the actual application requires a comprehensive trade-off on data availability, computing performance and demands from natural resources managers [6]. In this study, the integrated water storage capacity method was selected to calculate water conservation capacity since it takes into account the combined effects of canopy layer, litter layer and soil layer and can provide an evaluation and comparison on the forest water conservation function in each layer [7, 8], as well as the theoretical maximum storage capacity.

According to the integrated water storage capacity method, the three functional layers are divided into: canopy interception (C), litter water storage (L) and soil layer water storage (S). Thus, equation(1) (Table 1) shows the calculation of the total water conservation (WR) of forest ecosystems. Equation(2) (Table 1) shows the calculation of Canopy interception (C). Equation(3) (Table 1) shows the calculation of Litter water storage (L). Equation(4) (Table 1) shows the calculation of Soil layer water storage $(\mathrm{S})$. 
TABLE I. CALCULATION EQUATION OF WATER CONSERVATION

\begin{tabular}{|c|c|c|c|}
\hline $\begin{array}{c}\text { Total water conservation } \\
\text { (WR) }\end{array}$ & $\begin{array}{c}\text { Canopy interception } \\
\text { precipitation (C) }\end{array}$ & Litter water storage (L) & Soil layer water storage (S) \\
\hline$W R=C+L+S$ & $C=\sum_{i=1}^{n} \alpha_{\mathrm{i}} \times R \times A_{i}$ & $L=\sum_{i=1} \beta_{i} \times A_{i}$ & $\mathrm{~S}=\sum_{\mathrm{i}=1}^{\mathrm{n}} \gamma_{\mathrm{i}} \times D \times A_{i}$ \\
\hline $\begin{array}{l}\text { Where WR is Total water } \\
\text { conservation, C is canopy } \\
\text { interception precipitation, } \mathrm{L} \\
\text { is litter water storage, } \mathrm{S} \text { is } \\
\text { soil layer water storage. }\end{array}$ & $\begin{array}{l}\text { Where, } \alpha \text { is the canopy } \\
\text { interception rate }(\%), \mathrm{R} \text { is the } \\
\text { maximum daily precipitation } \\
(\mathrm{m}), \mathrm{A} \text { is the area }\left(\mathrm{m}^{2}\right) \text { and } \mathrm{i} \text { is } \\
\text { the vegetation type. }\end{array}$ & $\begin{array}{l}\text { Where, } \beta \text { is the maximum } \\
\text { water holding capacity of } \\
\text { litter layer }\left(\mathrm{t} / \mathrm{hm}^{2}\right), \mathrm{A} \text { is the } \\
\text { area }\left(\mathrm{hm}^{2}\right) \text { and } \mathrm{i} \text { is the } \\
\text { vegetation type. }\end{array}$ & $\begin{array}{l}\text { where, } \gamma \text { is the non-capillary } \\
\text { porosity of soil }(\%), D \text { is the } \\
\text { soil depth }(\mathrm{m}), \mathrm{A} \text { is the } \\
\text { area }\left(\mathrm{m}^{2}\right) \text { and i is the } \\
\text { vegetation type. }\end{array}$ \\
\hline
\end{tabular}

\section{B. Software Design}

Figure 1 shows the overall software design. FWAT can be divided into three layers: data management, application and visualization. Data management layer is mainly responsible for the reading, writing and storing data on forest type, soil, topography and climate. Application layer involves data pre-processing, water conservation capacity computing, and summarizing results. Visualization layer mainly includes mapping, charting, and table displaying of evaluation results.

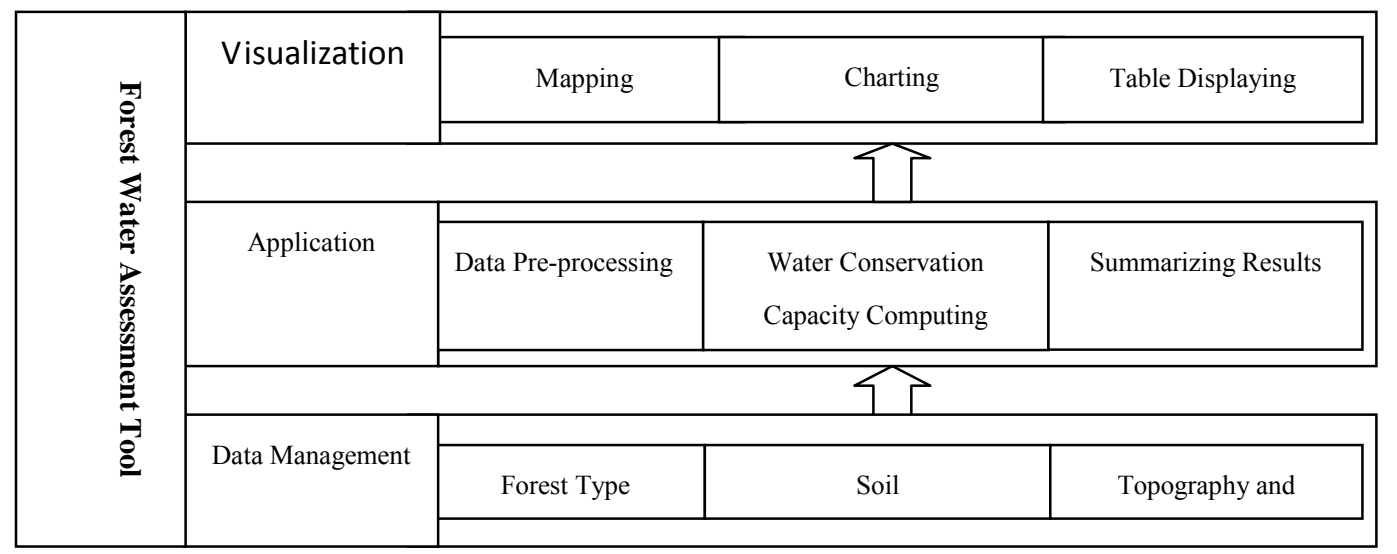

FIGURE I. THE OVERALL DESIGN OF FWAT

\section{Software Function Module}

Figure 2 shows the main function modules of FWAT.

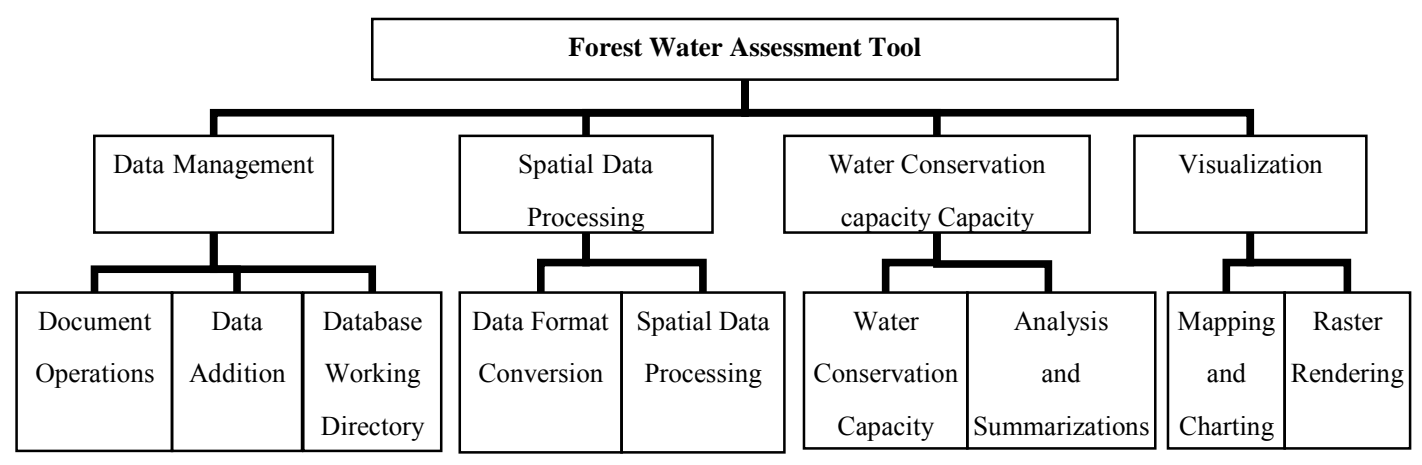

FIGURE II. THE FUNCTION MODULES OF SOFTWARE

The FWAT includes four modules, and they are as follows.

a) File management module including document operations, data addition, database, working directory. The main function is to read, write and save the data. b) Spatial data processing module including data format conversion and spatial data processing. The main function is to preprocess the data.

c) Water conservation capacity computing module including water conservation capacity calculation, analysis and summarization. The main function is to compute the water conservation capacity and analyze the result. 
d) Visualization module including mapping, charting and raster rendering. The main function is to create, display and output of thematic maps.

\section{CASE STUDY}

\section{A. Study Area and Data Inputs}

The Meijiang watershed, with an area of $6310.33 \mathrm{~km} 2$, located in the upstream of the Ganjiang River, the Poyang Lake basin of China. Situated in the transitional zone between the Central China Climate and the South China Climate Zone, the climate type in the study watershed is the subtropical monsoon humid climate. The climate here is warm and humid with abundant rainfall. The average annual rainfall is 1665.0 (mm), and the precipitation distribution gradually decreased from north to south.

The Meijiang watershed is covered by the subtropical evergreen broad-leaved forests with a forest coverage of over $70 \%$. The dominant tree species in this basin are masson pine and Chinese fir, and the parameters needed for the calculation of water conservation are shown in Table 2.

TABLE II. PARAMETERS FOR CALCULATING WATER CONSERVATION CAPACITY OF MASSON PINE AND CHINESE FIR [9]

\begin{tabular}{llll}
\hline \multicolumn{1}{c}{ Forest type } & $\begin{array}{c}\text { Canopy interception } \\
\text { rate (\%) }\end{array}$ & $\begin{array}{c}\text { Maximum water holding } \\
\text { capacity of litter layer } \\
\text { (t/hm2) }\end{array}$ & $\begin{array}{c}\text { Non-capillary porosity } \\
\text { of soil (\%) }\end{array}$ \\
\hline masson pine & 15.7 & 19 & \\
Chinese fir & 16.3 & 21.6 & 10.5 \\
\hline
\end{tabular}

For this case, masson pine, Chinese fir and non-woodland land cover information of the Meijiang watershed was derived from TM remote sensing image on October 31, 2005. Soil data are from the Harmonized World Soil Database version 1.1 (HWSD), where data sources in China are from the Second National Land Survey by Nanjing Soil Survey. The rainfall data is obtained from the interpolation of the climate data from 12 weather stations in Jiangxi Province by use of ANUSPLIN software.

B. Application of FWAT and Result

The main interface of software is shown in Figure 3.

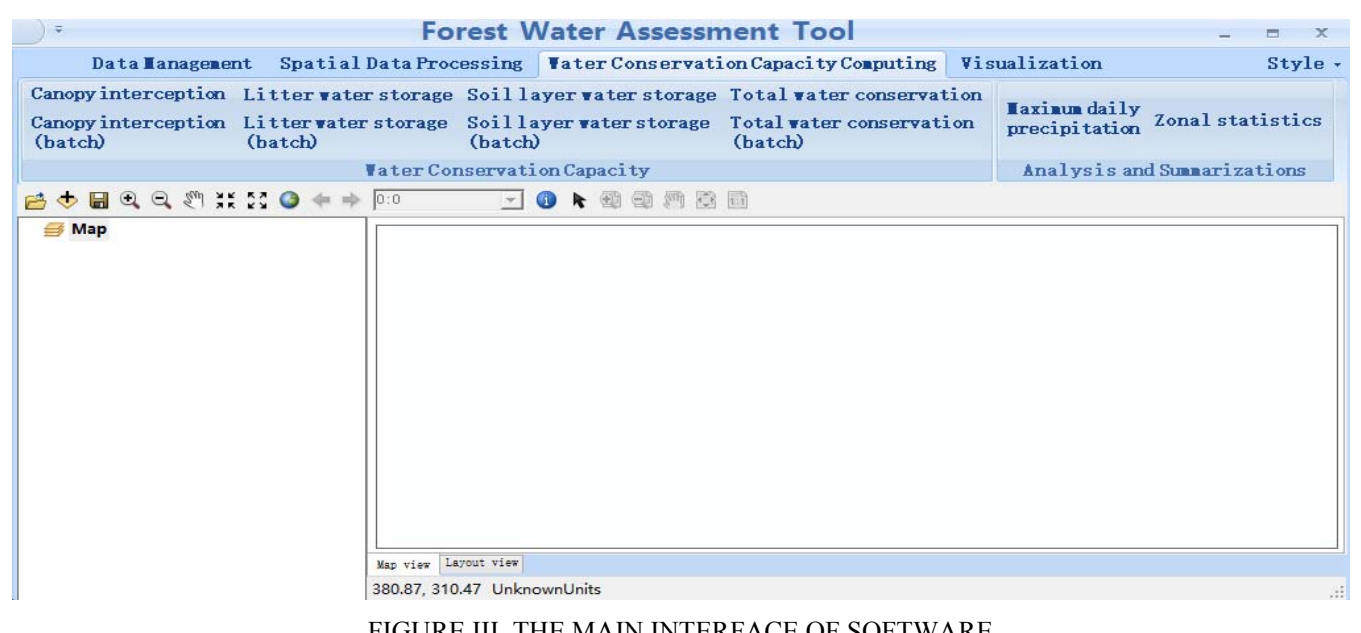

FIGURE III. THE MAIN INTERFACE OF SOFTWARE

1) Steps for water conservation capacity calculation

The steps for calculating water conservation capacity of the Meijiang watershed are as follows.

The raw data was preprocessed to extract the required data.

Canopy interception (C) can be estimated by inputting rainfall, forest type and canopy parameter table, and then setting up output file path (Figure 4(a)).
Litter water storage (L) can be computed by inputting forest type and litter parameter table, and then selecting output file path (Figure 4(b)).

Soil water storage(S) can be calculated by inputting forest type and soil parameter table, and then choosing output file path (Figure 4(c)).

Finally, the total water conservation capacity (WR) of the forest ecosystem in the Meijiang watershed can be calculated by combing the results of steps 2), 3) and 4) (Figure 4(d)). 


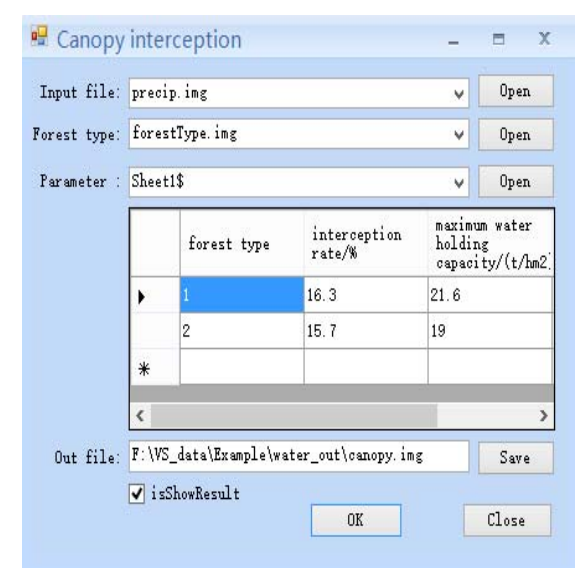

(A)

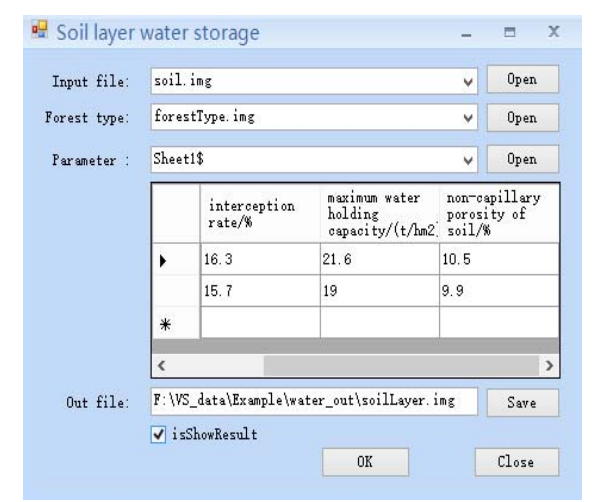

(C)

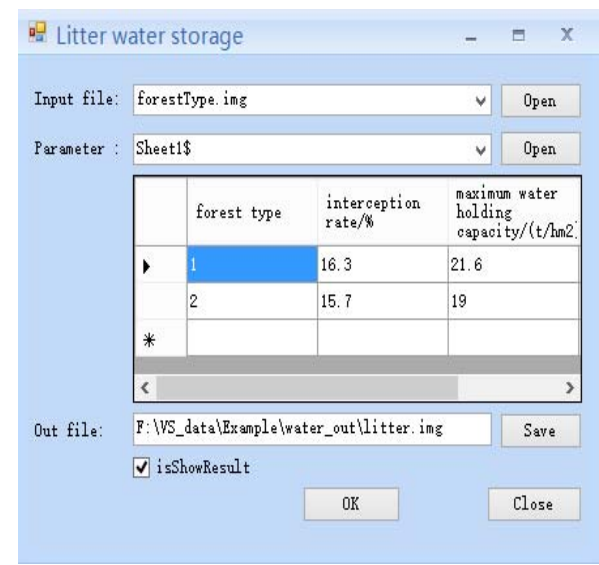

(B)

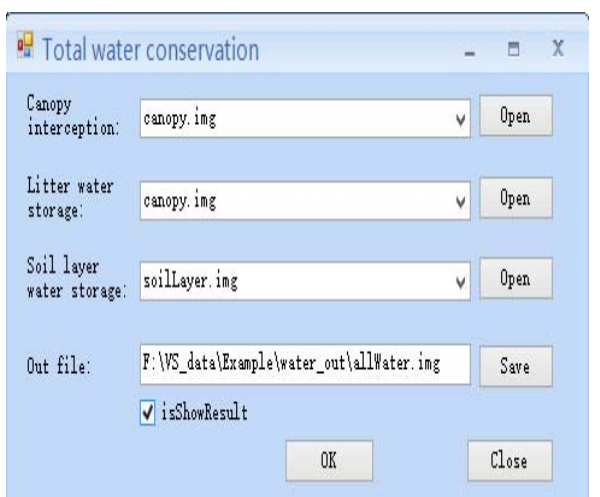

(D)

FIGURE IV. ILLUSTRATION OF CALCULATION STEPS, (A) CANOPY INTERCEPTION, (B) LITTER WATER STORAGE, (C) SOIL WATER STORAGE, (D) TOTAL WATER CONSERVATION CAPACITY

2) Results

Figure 5 shows the outputs of FWAT that show spatial distributions of water conservation capacity in different layers.

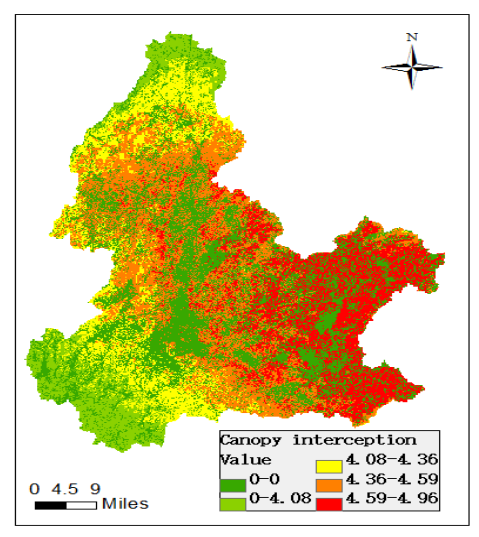

(A)

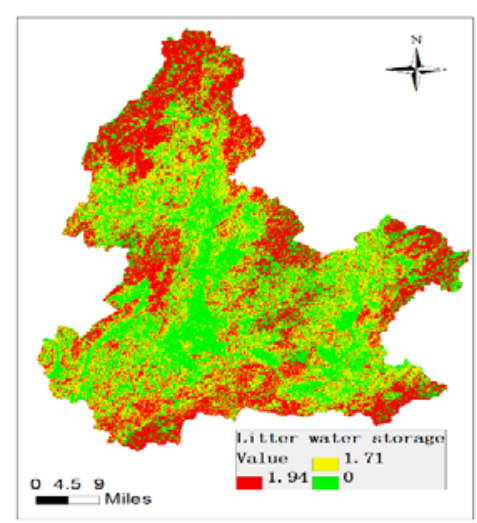

(B) 


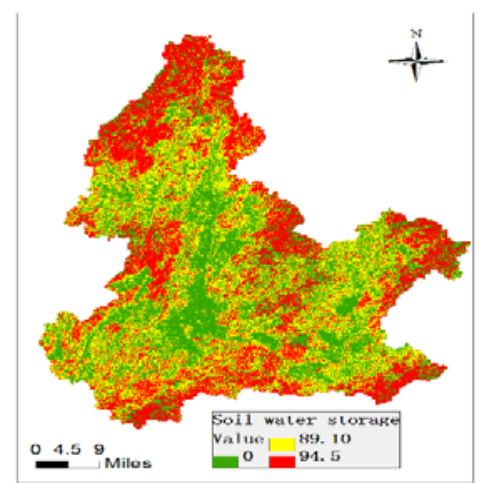

(C)

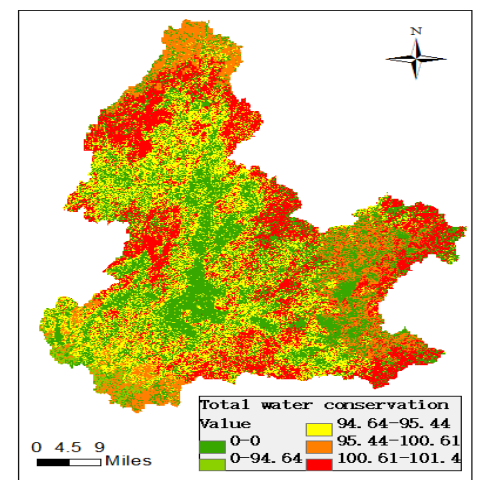

(D)

FIGURE V. ILLUSTRATION OF THE RESULTS OF THE CALCULATION, (A) CANOPY INTERCEPTION,(B) LITTER WATER STORAGE,(C) SOIL WATER STORAGE, (D) TOTAL WATER CONSERVATION OF THE MEIJIANG WATERSHED

As shown in Figure 5(d), the water conservation capacity in the eastern and northwestern of the Meijiang watershed is the highest where the main forest type is Chinese fir. Since the central part is mainly non-forest land, the water conservation capacity is the lowest. Due to the forest type in the southwest is poorly grown masson pine; the water conservation capacity is relatively low. Similarly, masson pine is mainly distributed in the sparse forest area; therefore, the water conservation capacity is also relatively low.

The statistical result of each forest type and function layers are shown in Table 3.

TABLE III. WATER CONSERVATION CAPACITY OF EACH FOREST TYPE AND LAYER $\left(10^{7} \mathrm{~m}^{3}\right)$

\begin{tabular}{llllc}
\hline & Canopy layer & Litter layer & Soil layer & Total water conservation capacity \\
\hline Chinese fir & $1.02(4.46 \%)$ & $0.45(1.97 \%)$ & $21.52(94.14 \%)$ & $22.86(100 \%)$ \\
masson pine & $0.98(4.62 \%)$ & $0.38(1.79 \%)$ & $19.86(93.72 \%)$ & $21.19(100 \%)$ \\
Total & $2(4.54 \%)$ & $0.83(1.88 \%)$ & $41.38(93.94 \%)$ & $44.05(100 \%)$ \\
\hline
\end{tabular}

ACKNOWLEDGMENT

As shown in Table 2, the water conservation capacity of Chinese fir is slightly higher than that of masson pine. Among the three functional layers, the soil layer has the highest water conservation capacity, followed by the canopy layer, and the lowest in the litter layer. As the relative contribution of soil layer reaches more than $90 \%$, therefore, the soil layer is the main part of forest water conservation. The results also suggest that the litter layer and canopy closure of the Meijiang watershed were poorly developed. That means in spite of high forest coverage in the Meijiang watershed, the plantation of Chinese fir and masson pine has little effect on the improvement of the water conservation capacity.

\section{Conclusion}

This paper presents self-developed software named FWAT by use of ENVI / IDL and ArcGIS Engine / C \# .NET hybrid programming languages to calculate the forest water conservation capacity based on the integrated water storage capacity method. Moreover, taking the Meijiang watershed as an application case, this paper shows the application of FWAT to calculate forest water conservation and obtain the spatial distribution of water conservation capacity and statistical results. The successful application in the Meijiang watershed shows that the FWAT is an efficient tool for natural resource managers to achieve a quick quantitative assessment of forest water conservation capacity in large watersheds.
This research was supported by National Key Research and Development Program of China (No. 2017YFC0505006), China National Science Foundation (No. 31770759).

\section{REFERENCES}

[1] W. Shao, et al. "The Water Resource Conservation of Forest Ecosystem in China," Res. Soil Water Conserv. 12, pp. 223-226, 2005.

[2] B. Zhang, et al. "Water conservation function and its measurement methods of forest ecosystem," Chin. J. Ecol. 28, pp. 529-534, 2009.

[3] X. Wang, H. Shen, and X. Li, "Concepts,processes and quantification methods of the forest water conservation at the multiple scales," Acta Ecol. Sin. 33, pp. 1019-1030, 2013.

[4] Q. He, "Technology and integration of RS and GIS and their use," Hydrogeol. Eng. Geol. 27, pp. 44-46, 2000.

[5] Y. Dile, et al. "Introducing a new open source GIS user interface for the SWAT model," Environ. Modell. Softw. 85, pp. 129-138, 2016.

[6] L. Jia, Q. Shao, and J. Liu, "Forest Conservation Estimation Based on the Integrated Storage Capacity Method_A Case Study of Xingguo County in Jiangxi," J. Northwest For. Univ. 27, pp. 83-87, 2012.

[7] B. Zhang, et al. "Water conservation of forest ecosystem in Beijing and its value," Ecol. Econ. 69, pp. 1416-1426, 2010.

[8] L. Liu, W. Cao, and Q. Shao, "Water Conservation Function of Forest Ecosystem in the Southern and Northern Pan River Watershed," Sci. Geogr. Sin. 36, 2016.

[9] D. Wu, Q. Shao, and J. Liu, "Assessment of Water Conservation Function of Forest Ecosystem in Taihe County, Jiangxi Province," Prog. Geogr. 31, pp. 330-336, 2012. 